\title{
Evaluation and differentiation of the Betulaceae birch bark species and their bioactive triterpene content using analytical FT-vibrational spectroscopy and GC-MS
}

\author{
Simona Cîntă-Pînzaru' ${ }^{1}$ Cristina A Dehelean ${ }^{2 *}$, Codruta Soica², Monica Culea ${ }^{3}$ and Florin Borcan²
}

\begin{abstract}
Background: Aiming to obtain the highest triterpene content in the extraction products, nine bark samples from the forest abundant flora of Apuseni Mountains, Romania were Raman spectroscopically evaluated. Three different natural extracts from Betula pendula Roth birch bark have been obtained and characterized using Fourier transform vibrational spectra.

Results: This study shows that principal components of the birch tree extract can be rapidly recognized and differentiated based on their vibrational fingerprint band shape and intensity. The vibrational spectroscopy results are supported by the GC-MS data. Based on IR and Raman analysis, one can conclude that all the extracts, independent on the solvent(s) used, revealed dominant betulin species, followed by lupeol.

Conclusions: Since Raman measurements could also be performed on fresh plant material, we demonstrated the possibility to apply the present results for the prediction of the highest triterpene content in bark species, for the selection of harvesting time or individual genotypes directly in the field, with appropriate portable Raman equipment.
\end{abstract}

Keywords: Natural extracts, Betulin, Betulinic acid, Lupeol, FT-Raman, FT-IR

\section{Background}

Because of its wide beneficial pharmacological activities, the bark of birch tree has been the subject of respect since ancient times, as well as the more recent subject of exhaustive research and natural extracts industry [1]. Betulin can be actually considered the first active principle isolated from a vegetal source [2]. The potential of plant origin products has been reevaluated for the use in still incurable diseases such as cancer and AIDS [1]. Many previously published reports have revealed the occurrence of lupane-based triterpenes across a multitude of plant specie [3].

Currently it is generally accepted that the outer bark of birch tree is rich in pentacyclic triterpene compounds

\footnotetext{
* Correspondence: cadehelean@umft.ro

${ }^{2}$ Faculty of Pharmacy, Victor Babeş University of Medicine and Pharmacy, 2nd Eftimie Murgu Sq. Timişoara 300041, Romania

Full list of author information is available at the end of the article
}

such as betulinic acid (BA, 33-hydroxy-20(19)-lupaen28-oic acid), betulin (B, lup-20(29)-ene-3 $\beta, 28$-diol), lupeol (L, Lup-20(29)-en-3-ol) and other minor components, such as oleanolic acid, ursolic acid and betulinic aldehyde [4]. The pentacyclic triterpenes are known to have a wide-range of pharmaceutical activities, among them possessing anti-virus, anti-inflammatory, anticancer and other properties [5]. Betulin reaches the highest percentage within the composition of triterpenes from the birch bark [6] and exhibits significant therapeutic activity, acting as antitumor, antiviral and antiseptic agent. [4] Betulinic acid, the oxidation product of betulin, reveals important anti-HIV-1 activity and specific cytotoxic activity against different tumor cell lines [3]. Betulin and betulinic acid have been involved in chemical modulation, leading to highly active derivatives, some of them comparable to clinically used drugs [3,7].

\section{(Chemistry Central}


Summarizing previous data findings, the betulin content is dominant, whereas the betulinic acid content is much lower [8]. However, plant species from different geographical locations might reveal a variable composition of the extraction product, which is essential to be accurately characterized for biological use, including the content in BA and B.

During the last years, especially infrared spectroscopy (IR) has been introduced as a very efficient and nondestructive analytical tool for the reliable identification of triterpenes resulted from various extraction methods. [9-12] Our previous study [9] combined for the first time complementary FT-IR and FT-Raman techniques for characterization of the birch three leaves, buds and bark. However, the limits of NIR spectroscopy technique require complementary analysis methods for identification of the expected compounds. So far, a great number of NIR calibrations have been perfected in order to predict in a simultaneous manner the amount of volatile and non-volatile substances in different plants; as opposed to NIR measurements, the fundamental absorption bands noticed in the mid-infrared (MIR) range can offer concrete information regarding functional groups of the individual species [12].

Raman spectroscopy is currently recognized as a flexible, accurate and high sensitive technique, that is currently widely applied in a plenty of domains, as recently excellent reviewed the current [13] and former editor of the topic journal [14-16].

Since the Betulaceae species are largely represented in the European flora, they represent a valuable resource of potentially pharmaceutical products and therefore must be investigated in a nondestructive, rapid and sensitive manner. Thus, the identification of birch bark material in close relation to the geographical location is crucial in ensuring the quality and efficacy of the raw sample
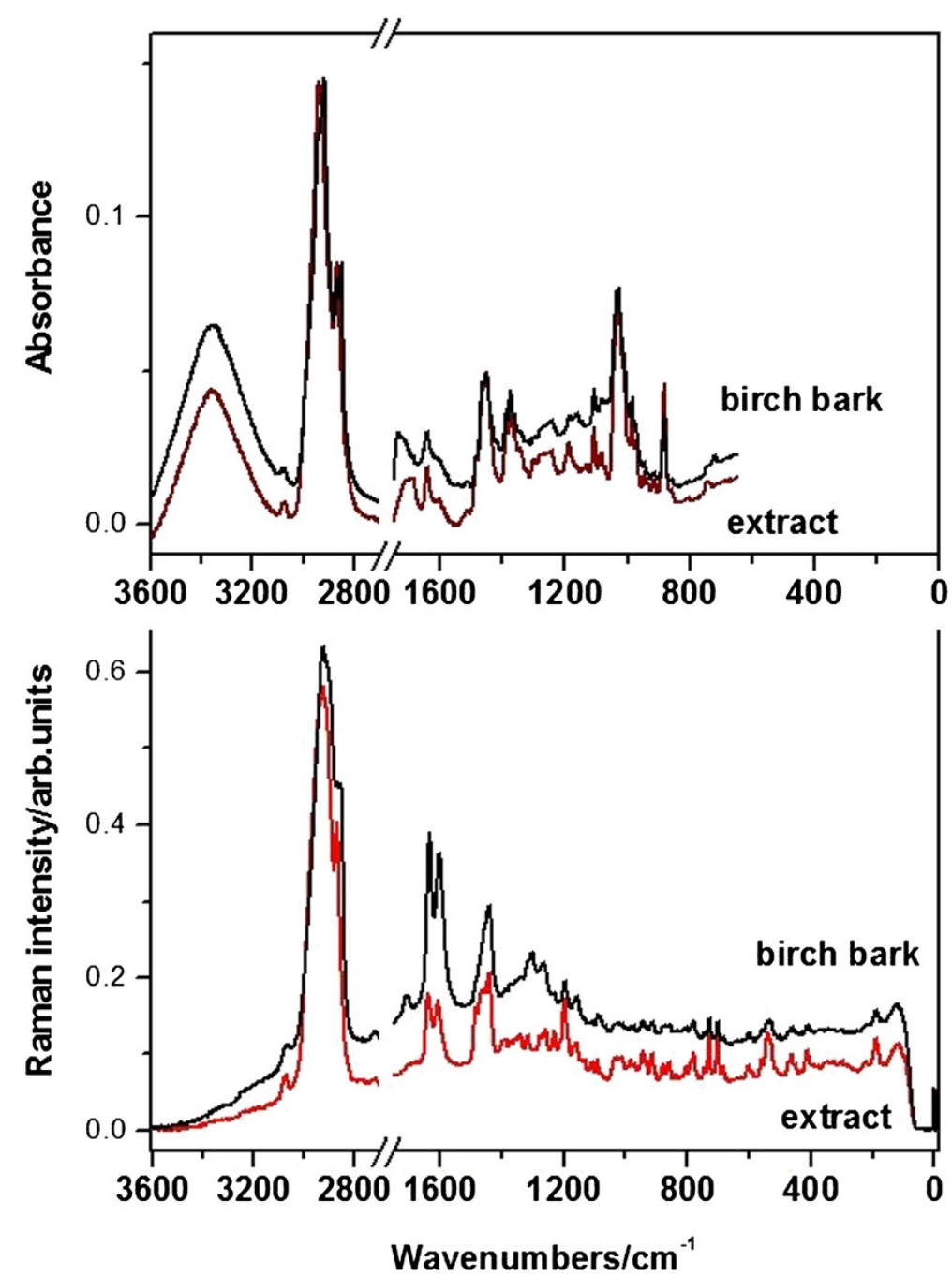

Figure 1 ATR-FT-IR and FT-Raman spectra of the raw birch bark that exhibits the highest $\mathrm{I}_{1633} / \mathrm{I}_{1601}$ Raman ratio and the extract product $\mathrm{BC} 1$. 
before it is converted to the final product. Natural product companies are continuously seeking a faster and inexpensive validation method considering that the traditional wet chemistry analysis does not offer these advantages.

In this work, we employed FT-Raman and FT-IR spectroscopy in conjunction with GC-MS to characterize the raw bark and natural extract products obtained from the Betula pendula Roth species, abundant in the Aninei Mountains, Romania. Additionally, nine bark samples harvested from a birch forest in Apuseni Mountains, Romania, have been Raman investigated, in order to evaluate the spectral response from different specimens and to use this material as reference point for extracts. Further aim of these investigations was to evaluate the potential of FT-vibrational spectroscopy to directly identify the main active compounds from birch bark natural extract products.

\section{Results and discussion}

FT-vibrational spectra of the raw birch bark from Aninei Mountains and one of the extract products, $\mathrm{BC} 1$, are shown in the Figure 1. At a first glance, the spectral pattern is rather similar, exhibiting same main band positions and relative intensities both in the IR and Raman. Small differences are observed in the $1788-1633 \mathrm{~cm}^{-1}$ IR absorbance as well as in the $1400-1250 \mathrm{~cm}^{-1}$ Raman range. As the extraction product is consistent with the pentacyclic triterpenes structure as confirmed by the GC-MS, the vibrational FT-IR and Raman spectra directly revealed the triterpenes specific content of the raw bark.

In order to evaluate the possible variation of triterpene content from one tree to another, and from one area to another, nine different birch located in our area were subject of Raman investigation. Figure 2 presents the FT-Raman spectra collected from two distinct bark points from each of nine birch trees from spontaneous forest flora area in the Apuseni Mountains, Romania. These raw materials were used to evaluate in detail with vibrational spectroscopy the birch bark composition as a reference point for extracts and to prove the applicability of this technique for such an application.

The spectral shape is rather similar with a specific major difference. The relative intensity ratio of the band at $1633 \mathrm{~cm}^{-1}$ representative for the triterpenes $[6,9,17,18]$ and the band at $1601 \mathrm{~cm}^{-1}$ assigned to other species than triterpenes, $\mathrm{I}_{1633} / \mathrm{I}_{1601}$ varies from 0.9 to 1.1 in the nine samples. This variation depends on a lot of factors like the age of the tree, the sun exposure, the soil and others. The origin of the band at $1601 \mathrm{~cm}^{-1}$ is uncertain, since many organic compounds exhibit such band. According to our previous vibrational assignments of betulinic acid [17] and betulin [6], this band is absent from the triterpene spectra. Therefore, the band at $1601 \mathrm{~cm}^{-1}$ could suggest other wood content associated to the impurities resulted from extraction protocol (Figure 1).

\section{IR and Raman spectra of the extraction products}

The ATR-FT-IR and FT-Raman spectra of the obtained extract products are displayed in the Figure $3 \mathrm{~A}$ and $\mathrm{B}$,

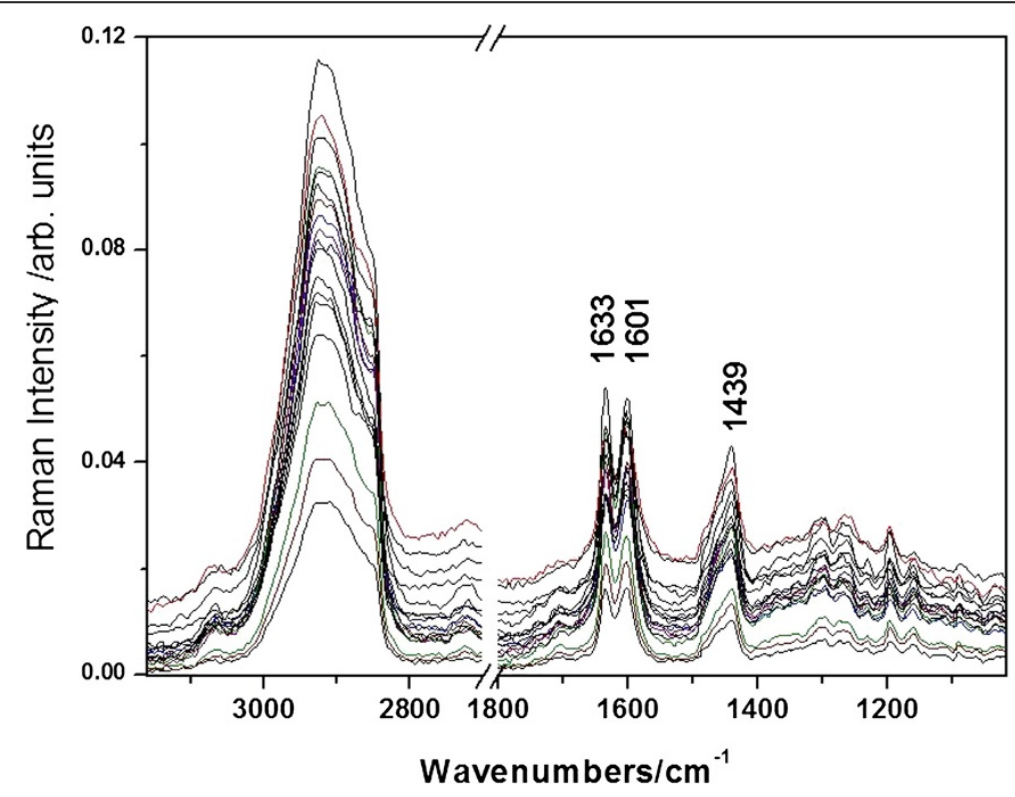

Figure 2 FT-Raman spectra collected from two distinct bark points from each of nine birch trees from spontaneous forest flora area in the Apuseni Mountains, Romania. The relative intensity of the bands at $1633 \mathrm{~cm}^{-1}$ representative for the triterpenes and $1601 \mathrm{~cm}^{-1}$ assigned to other species than triterpenes, $\left.\right|_{1633} / I_{1601}$ varies from 0.9 to 1.1 in the nine bark samples. 
respectively, in comparison with the spectrum of the raw birch bark that exhibits the highest I ${ }_{1633} / I_{1601}$ Raman ratio.

\section{IR Analysis}

The FT-IR spectral pattern of all the three extracts is rather similar, exhibiting the same main band positions and relative intensities. Small differences are observed in the $1788-1633 \mathrm{~cm}^{-1}$ IR absorbance range. IR absorbance of the three extracts revealed rather similar molecular composition, based on the main characteristic IR absorption of the triterpene. Similarities with the spectrum of the pure, unprocessed bark are remarkable. Exception in the spectral feature is observed for the band at $1735 \mathrm{~cm}^{-1}$ attributable to the $v(C=O)$ mode, that is prominent in the bark spectrum.

$\mathrm{MeOH}$ solvent from extraction protocol also introduces differences in the spectrum of the corresponding extract (specific bands at 882 and $3222 \mathrm{~cm}^{-1}$, Figure 3A.).

ATR-FT-IR spectra of the three extract products have been compared to those reported from isolated compounds extracted from the Betula utilis and Hyptis suaveolens from Hymalaya [11] or Betulaceae cortex, Betula pendula Roth [10] from Central Europe, reported so far. The ATR-FT-IR spectra of the reference compounds, betulin, betulinic acid and lupeol are displayed in the
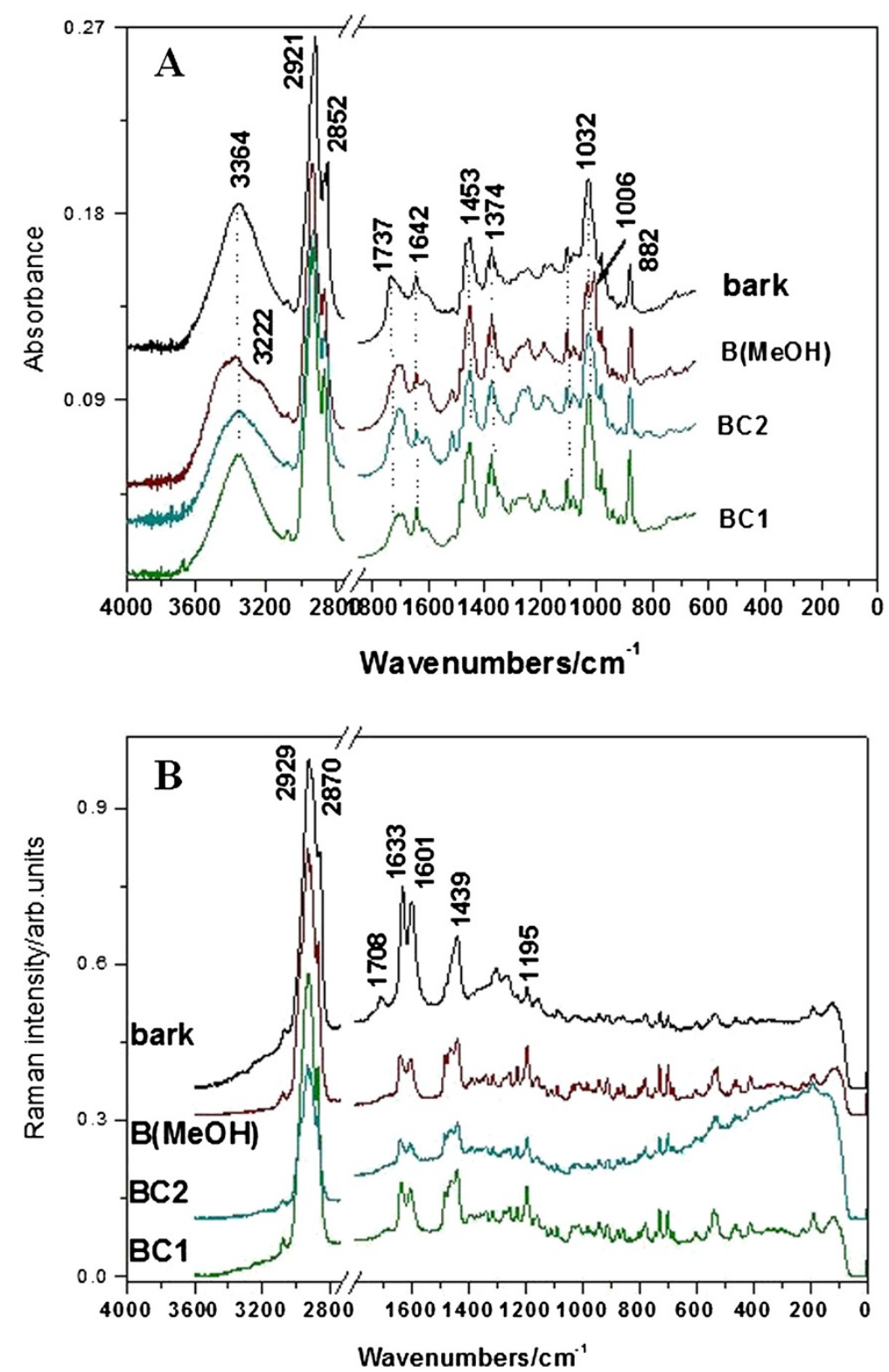

Figure 3 The ATR-FT-IR (A) and FT-Raman spectra (B) of the three extract products compared to those of the raw birch bark. 
Figure 4, in comparison with the IR absorbance of raw bark. The "symbol denotes the specific bands of each reference compound that could be used for triterpenes differentiation.

The IR band positions observed in our spectra and their assignments are summarized in the Table 1, in comparison with the IR main bands of betulin, betulinic acid and lupeol, recorded in the $4000-650 \mathrm{~cm}^{-1}$ range. The band positions marked in bold are suitable for triterpenes differentiation and correspond to those with the symbol "in Figure 4.

Analyzing the IR spectra of the isolated compounds from Betulaceae extracts with dry column chromatography, a recent study [10] concluded that triterpene substances betulin, betulinic acid and lupeol, isolated from external birch bark (Betula Pendula Roth) give identical, characteristic signals and absorbance as reference standards. Those spectra have been recorded using $\mathrm{KBr}$ pellet technique. However, the reference standard IR spectra reported cannot differentiate between betulin and lupeol. Furthermore, other reference [11] claims that authentic betulin exhibits distinctive bands at 3430, $1716,1641,1600,1581,1291,881 \mathrm{~cm}^{-1}$, whereas betulinic acid at $3508,1710,1690,1641,1600,1580,1290 \mathrm{~cm}^{-1}$, as summarized in the Table 1 for comparison.

Taking a closer inspection to the Figure 4 it is noticed that the band at $1600 \mathrm{~cm}^{-1}$ is absent in the reference spectra. Its origin is associated with other organic compounds than triterpenes, as mentioned above. Moreover, the band shape in the range $1032-1006 \mathrm{~cm}^{-1}$ of the bark reflects the triterpene contribution, since betulin is responsible for the contribution at $1006 \mathrm{~cm}^{-1}$ whereas betulinic acid and lupeol exhibit contribution at $1032 \mathrm{~cm}^{-1}$ (Figure 4). Betulinic acid exhibits a strong characteristic IR band at 1681 that allow fast differentiation among triterpene species. However, this fingerprint is not distinct observable in the bark spectrum, suggesting that its contribution content is minor. The high wavenumbers range of the bark spectrum is less suitable for triterpenes differentiation, since the bark IR contribution is an envelope of the tree specific spectral features (Figure 4). These results suggest that IR spectroscopy allows differentiate betulin, betulinic acid and lupeol, in spite of their high structural similarity. IR only could provide information for triterpene differentiation and quantitative estimation in the $1032-1006 \mathrm{~cm}^{-1}$ absorbance range of the raw bark or the extract product. Keeping this in mind, we are able to direct evaluate and compare the three extract products concerning the triterpenes content/impurity ratio. We calculated the relative intensity ratio of the bands $I_{1032} / I_{1601}$ whose IR spectra are shown in the Figure 3A. The values of 3.32, 1.7 and 1.47 for the $\mathrm{BC} 1, \mathrm{BC} 2$ and $\mathrm{B}(\mathrm{MeOH})$ extracts respectively, suggest that $\mathrm{BC} 1$ extract presents the highest purity. Furthermore, evaluation of the relative betulin content could be achieved using the betulin IR fingerprint band at $1006 \mathrm{~cm}^{-1}$. Consequently, the corresponding ratios of 2.29, 1.519 and 1.52 respectively, suggests that $\mathrm{BC} 1$ extract exhibits the betulin highest content, whereas the others revealed similar lower content, independent on the solvent(s) used. The vegetal tissues contain complex mixtures of substances known to possess

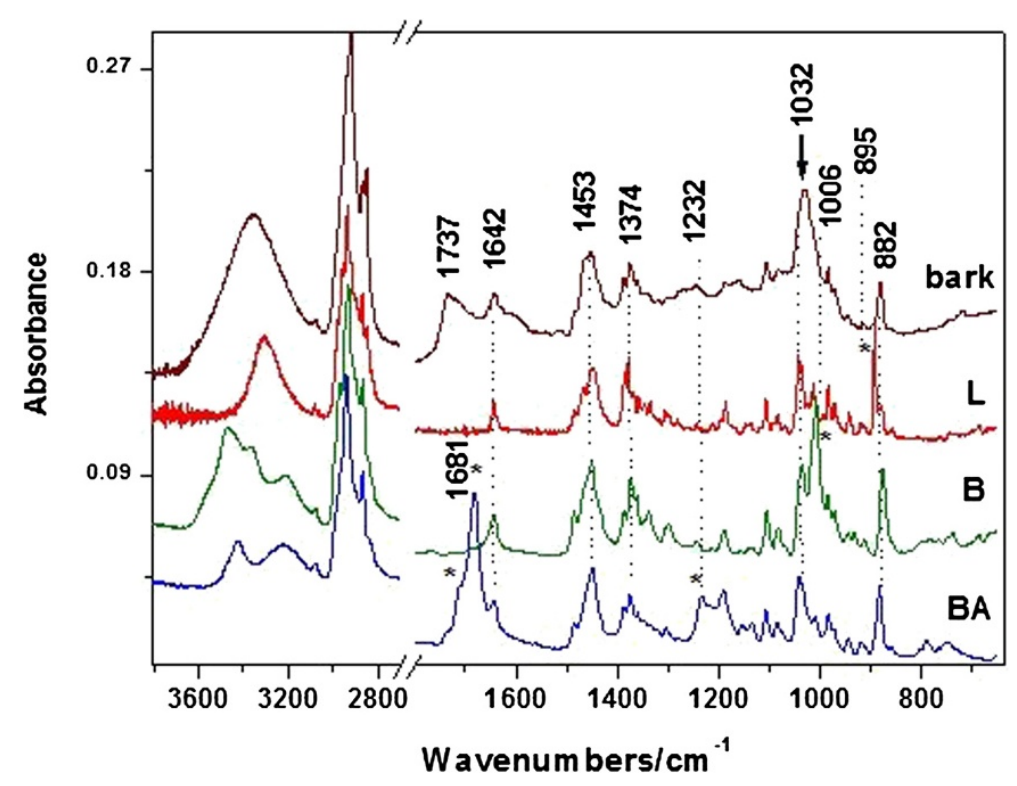

Figure 4 The ATR-FT-IR spectra of the reference compounds, betulin, betulinic acid and lupeol in comparison with the absorbance of raw bark. The * symbol denotes the specific band of each reference compound that could be used for triterpenes differentiation. 
Table 1 The observed IR bands $\left(\mathrm{cm}^{-1}\right)$ of the extract compounds of Betulaceae species, and the pure references species betulin (B), lupeol (L) and betulinic acid (BA) together with their assignments based on our previous DFT calculations [3] of betulin

\begin{tabular}{|c|c|c|c|c|c|c|}
\hline IR & IR & IR & IR & IR & IR & Assignments \\
\hline $\begin{array}{l}\text { Betula utilis } \\
\text { extract } \\
\text { from } \\
\text { ref. [11] }\end{array}$ & $\begin{array}{l}\text { Isolated } \\
\text { triterpenes } \\
\text { from Betula } \\
\text { Pendula } \\
\text { Roth, } \\
\text { ref. [10] }\end{array}$ & $\begin{array}{l}\text { Extract BC1 } \\
\text { from Betula } \\
\text { Pendula } \\
\text { Roth }\end{array}$ & $\begin{array}{l}\text { Betulin } \\
\text { (B) }\end{array}$ & $\begin{array}{l}\text { Betulinic } \\
\text { acid (BA) }\end{array}$ & $\begin{array}{l}\text { Lupeol } \\
\text { (L) }\end{array}$ & \\
\hline 3433 (B) & - & - & $3471 \mathrm{vs}$ & 3431 & - & $v(\mathrm{OH})$ \\
\hline - & - & - & 3465 sh & - & - & $v(\mathrm{OH}))$ \\
\hline \multirow[t]{3}{*}{ - } & $3384(B A)$ & $3362 \mathrm{~s}$ & $3362 \mathrm{~s}$ & - & $3309 \mathrm{~s}$ & $v(\mathrm{OH})$ \\
\hline & 3348 (B) & & & & & \\
\hline & $3308(L)$ & & & & & \\
\hline- & - & - & 3212 m & 3225 & - & $v(\mathrm{OH})$ \\
\hline \multirow[t]{3}{*}{ - } & \multirow[t]{3}{*}{-} & \multirow[t]{3}{*}{2940 vs } & \multirow[t]{3}{*}{2968 vs } & \multirow[t]{3}{*}{2943 vs } & $2982 \mathrm{~s}$ & \multirow{3}{*}{$\begin{array}{l}v_{\text {as }}\left(\mathrm{CH}_{3}\right)+v_{\text {as }}\left(\mathrm{CH}_{2}\right) \\
+v_{\text {as }}(\mathrm{CH})\end{array}$} \\
\hline & & & & & $2957 \mathrm{~s}$ & \\
\hline & & & & & 2942 vs & \\
\hline - & - & - & 2929 vs & - & 2928 sh & $\begin{array}{l}V_{\mathrm{as}}\left(\mathrm{CH}_{2}\right)+v\left(\mathrm{CH}_{2}\right) \\
+v(\mathrm{CH})\end{array}$ \\
\hline \multirow[t]{3}{*}{ - } & $2870(\mathrm{BA})$ & \multirow[t]{3}{*}{$2867 \mathrm{~s}$} & \multirow[t]{3}{*}{2866 vs } & \multirow[t]{3}{*}{2878 vs } & 2874 vs & \multirow[t]{3}{*}{$+v\left(\mathrm{CH}_{2}+v\left(\mathrm{CH}_{2}\right)\right.$} \\
\hline & $2868(B)$ & & & & $2845 \mathrm{sh}$ & \\
\hline & $2872(L)$ & & & & & \\
\hline $\begin{array}{l}1725(B) \\
1672(B A)\end{array}$ & 1686, BA & $\begin{array}{l}\text { 1709-1684, } \\
\text { broad }\end{array}$ & $\begin{array}{l}1735 \mathrm{~W} \\
1708 \mathrm{sh}\end{array}$ & $\begin{array}{l}1716 \text { sh, } \\
1681 \text { vs }\end{array}$ & - & $v(\mathrm{C}=0)$ \\
\hline \multirow[t]{2}{*}{$1648(B)$} & 1638)(B) & \multirow[t]{2}{*}{1642} & \multirow[t]{2}{*}{$1642 \mathrm{~m}$} & \multirow[t]{2}{*}{$1642 \mathrm{~m}$} & \multirow[t]{2}{*}{1642 m } & \multirow{2}{*}{$\begin{array}{l}\delta\left(\mathrm{CH}_{2}\right)+v((\mathrm{C}=\mathrm{C}) \\
+\delta(\mathrm{C}-\mathrm{C}-\mathrm{H})\end{array}$} \\
\hline & $1630(\mathrm{~L})$ & & & & & \\
\hline $\begin{array}{l}1600(B) \\
1560(B)\end{array}$ & - & 1601 & - & - & - & - \\
\hline - & $\begin{array}{l}1468(\mathrm{~L}) \\
1432(\mathrm{BA}, \mathrm{B})\end{array}$ & $\begin{array}{l}1484 \mathrm{~m} \\
1452 \mathrm{~s}\end{array}$ & $\begin{array}{l}1485 \mathrm{~m} \\
1450 \mathrm{~s}\end{array}$ & 1451 & 1453 m & $\delta\left(\mathrm{CH}_{3}\right)+\delta\left(\mathrm{CH}_{2}\right)$ \\
\hline- & $\begin{array}{l}1362(\mathrm{O}-\mathrm{H}, \\
\mathrm{BA}) ; \\
1380(\mathrm{~L}) \\
1388(\mathrm{~B})\end{array}$ & $1373 \mathrm{~m}$ & 1373 m & $1377 \mathrm{~m}$ & 1374 m & $\delta\left(\mathrm{CH}_{3}\right)+\delta\left(\mathrm{CH}_{2}\right)$ \\
\hline $\begin{array}{l}1230(\mathrm{~B}) \\
1240(\mathrm{BA})\end{array}$ & - & - & - & $1232 \mathrm{~m}$ & - & $\delta(\mathrm{OH})+\mathrm{T}\left(\mathrm{CH}_{2}\right)+\delta(\mathrm{CH})$ \\
\hline- & $1156(\mathrm{BA})$ & $1190 \mathrm{~m}$ & $1190 \mathrm{~m}$ & $1190 \mathrm{~m}$ & $1190 \mathrm{~m}$ & $\begin{array}{l}v(\mathrm{C}-\mathrm{C})+\delta(\mathrm{OH}) \\
+\mathrm{T}\left(\mathrm{CH}_{2}\right)+\delta(\mathrm{CH})\end{array}$ \\
\hline $1028(B A)$ & $920(L)$ & $1028 \mathrm{~s}$ & $1032 \mathrm{~ms}$ & $1043 \mathrm{~m}$ & 1046 m & $\begin{array}{l}v(\mathrm{C}-\mathrm{O}) \text { from } \mathrm{CH}_{2}-\mathrm{OH}, \\
+\delta(\mathrm{CH})+\rho\left(\mathrm{CH}_{3}, \mathrm{CH}_{2}\right)\end{array}$ \\
\hline \multirow[t]{2}{*}{-} & \multirow[t]{2}{*}{-} & $1006 \mathrm{sh}$ & \multirow[t]{2}{*}{1006 vs } & \multirow[t]{2}{*}{-} & \multirow[t]{2}{*}{-} & \multirow{2}{*}{$\begin{array}{l}v(\mathrm{C}-\mathrm{O})+\delta(\mathrm{CH}) \\
+\rho\left(\mathrm{CH}_{3}-\mathrm{CH}_{2}\right)\end{array}$} \\
\hline & & 984 m & & & & \\
\hline 881 (B) & $920(L)$ & $881 \mathrm{~ms}$ & $875 \mathrm{~ms}$ & $885 \mathrm{~ms}$ & $895 \mathrm{~s}$ & $\begin{array}{l}\omega(\mathrm{H}-\mathrm{C}-\mathrm{H}) \\
\text { umbrella alkene }\end{array}$ \\
\hline
\end{tabular}

Abbreviations: v-very, s- strong, m-medium, sh-shoulder, $v$-stretching, $\delta$-bending, $\tau$-torsion, $\rho$-rocking; B-betulin, BA-betulinic acid, L-lupeol.

synergistic activities. $[19,20]$ Structure-activity relationship studies [7,21] revealed that C-28 carboxylic acid of betulinic acid was very important for its cytotoxicity. A recent study for the simultaneous extraction and determination of betulin and betulinic acid in white birch bark using RP-HPLC has been reported. [22] The extraction was tested using different solvents, leading to the conclusion that $95 \%$ ethanol in water is a good 
extraction solvent which allowed extraction of triterpenes at a highest content. Separation was achieved on a reversed phase $\mathrm{C}_{18}$ column with acetonitrile/water 86:14 $(\mathrm{v} / \mathrm{v})$. Detection was accomplished with UV detection at $\lambda=210 \mathrm{~nm}$. The bioactive triterpenes in white birch bark were simultaneously determined, significant variations in the content of betulin and betulinic acid in white birch bark from different China locations being observed [22].

\section{FT-Raman analysis of the extraction products}

FT-Raman spectra of the three extracts shown in the Figure 3B exhibit similar spectral pattern concerning the band positions and relative intensities. Major difference is noted in the Raman background, generally associated with fluorescence impurities. The highest signal-to-noise ratio has been obtained from the $\mathrm{BC} 1$ sample followed by $\mathrm{B}(\mathrm{MeOH})$. The natural birch bark spectrum exhibits characteristic Raman bands of the extract products, assigned to the pentacyclic triterpene, besides other components (extra bands at 1708 and $1301 \mathrm{~cm}^{-1}$ ).

In order to characterize the Raman behavior of the extracts, the reference Raman spectra of the betulinic acid betulin and lupeol have been loaded (Figure 5). The three lupan skeleton compounds are similar, the difference being the $-\mathrm{COOH},-\mathrm{CH}_{2}-\mathrm{OH}$ and $-\mathrm{CH}_{3}$ functional groups, respectively. These differences are reflected in the Raman spectra by the presence of the specific distinct bands, as shown in detail in the Figure 6 and 7 for the high and low wavenumbers range, respectively. The Raman spectra of the three extracts, $\mathrm{BC} 1, \mathrm{~B}(\mathrm{MeOH})$, and $\mathrm{BC} 2$ respectively are also shown in the same bottom figure (Figures 6 and 7), for eye guidance and a better comparison.

Since the best Raman signal/noise ratio has been recorded in the case of $\mathrm{BC} 1$ extract, its FT-Raman spectrum was displayed in comparison with the pure betulin, lupeol and betulinic acid species spectra. Taking a closer look at the high wavenumber region (Figure 6), one can observe that the $\mathrm{BC} 1$ Raman bands follow the envelope of the three reference spectra, with the maximum centered on betulin representative band and shoulders characteristic for clearly resolved bands of lupeol. Because of the band shape complexity and overlap, this Raman spectral range does not allow clear triterpene species differentiation. In the low wavenumbers range (Figure 7), betulinic acid exhibits specific weak
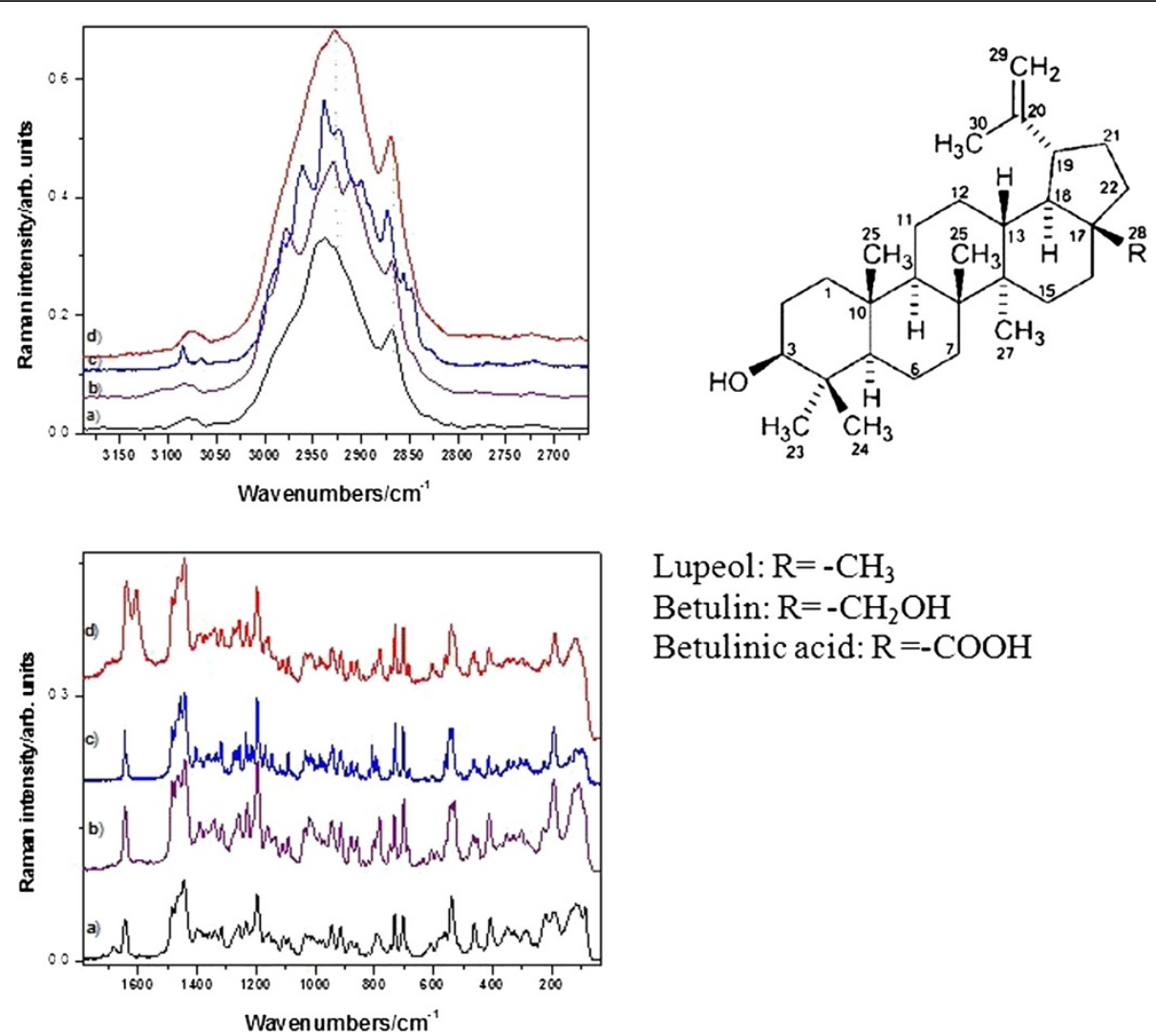

Lupeol: $\mathrm{R}=-\mathrm{CH}_{3}$

Betulin: $\mathrm{R}=-\mathrm{CH}_{2} \mathrm{OH}$

Betulinic acid: $\mathrm{R}=-\mathrm{COOH}$

Wavenumbers $/ \mathrm{cm}^{-1}$

Figure 5 High (top) and low (bottom) wavenumbers spectral range of the FT-Raman spectra of the betulinic acid (a), betulin (b), lupeol (c) and BC1 extract (d). Excitation: $350 \mathrm{~mW}, 1064 \mathrm{~nm}$. The molecular structure of the three lupan skeleton compounds is shown in the right. 


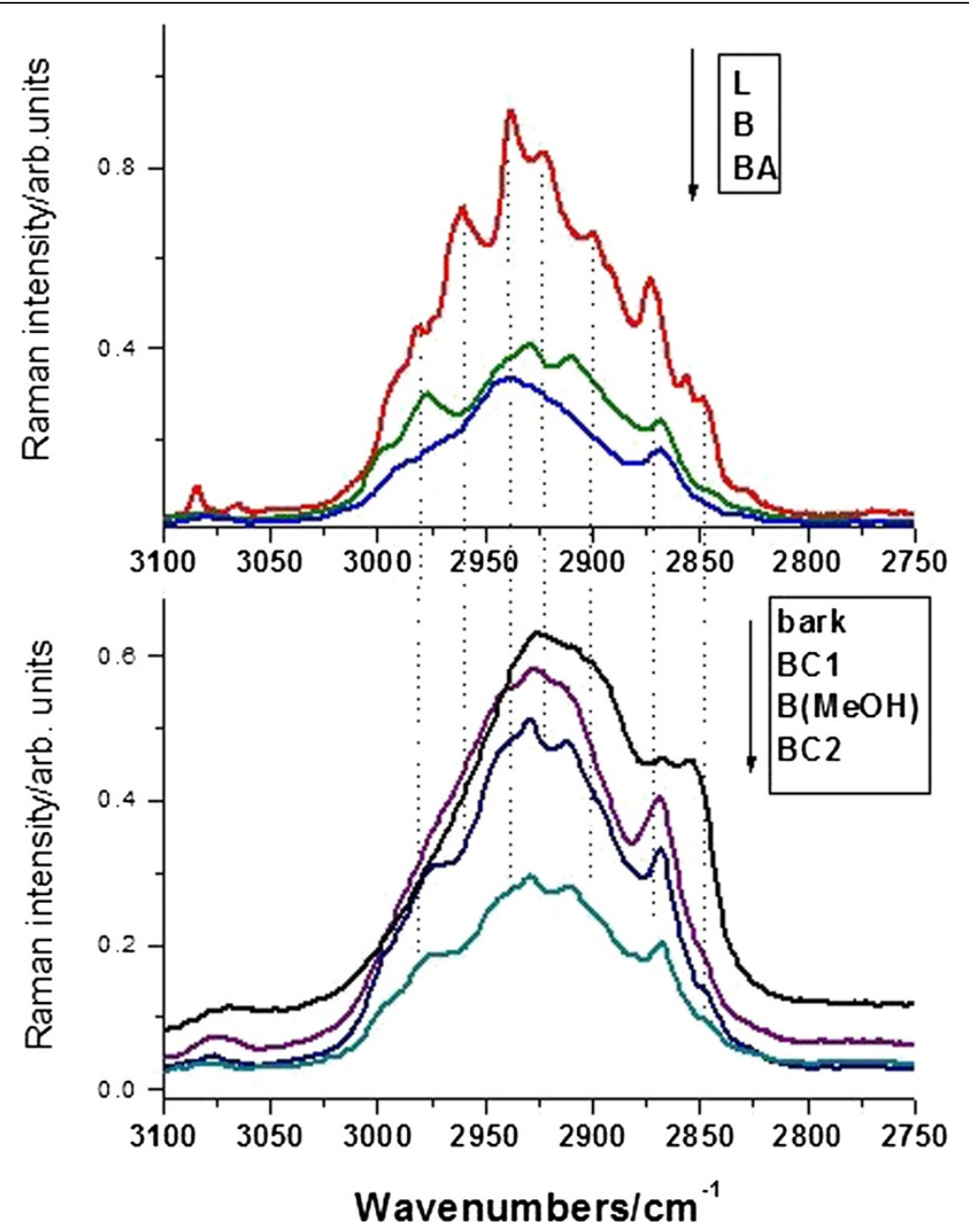

Figure 6 Bottom: high wavenumber range of the FT-Raman spectra of the $\mathrm{BC} 1, \mathrm{~B}(\mathrm{MeOH}), \mathrm{BC} 2$ extracts and bark (bottom), compared with the reference spectra of betulin (B), lupeol (L) and betulinic acid (BA), respectively, (top). The arrow indicates the display order. Excitation: $350 \mathrm{~mW}, 1064 \mathrm{~nm}$.

Raman bands (IR strong) at 1718 and $1681 \mathrm{~cm}^{-1}$ (marked with * symbol), whereas lupeol showed strong Raman fingerprint at 1457 and $1408 \mathrm{~cm}^{-1}$ assigned to the methyl deformation modes (Table 1). These fingerprint bands are less discernable individually in the triterpene mixture due to the weak intensity in the case of $\mathrm{BA}$, which is less representative in the overall extract content. Raman spectrum of the $\mathrm{BC} 1$ extract contains all the characteristic bands of the pure betulin, located at 2979 (shoulder), 2929, 2909, 2870, 1642, 1486, 1465, 1441, 1194, 780, 732, $702 \mathrm{~cm}^{-1}$. These bands are present in all the extraction products or in the raw bark spectra (Figures 6 and 7). Additionally, a distinct strong band located at $1601 \mathrm{~cm}^{-1}$, is constantly observed (Figure 7, rectangle pointed out), also showed above in IR spectrum. It must be pointed out that the $\mathrm{C}=\mathrm{C}$ Raman mode of the three triterpene is located at $1642 \mathrm{~cm}^{-1}$, whereas the raw bark showed this broaden band centered at
$1633 \mathrm{~cm}^{-1}$. A possible explanation would be the presence of other aromatic compound(s), which would be also responsible for the "impurity" band at $1601 \mathrm{~cm}^{-1}$. In conclusion, the betulin spectral Raman signature is dominant in the Raman spectra of the extracts, suggesting its content dominance, whereas betulinic acid and lupeol are not directly detectable due to their weak overall Raman contribution within overlapped betulin bands. Raman spectroscopy could provide quantitative information concerning the triterpene content in the final extract products by analyzing the relative intensity ration of the $1642 \mathrm{~cm}^{-1}$ ( $\mathrm{C}=\mathrm{C}$ mode) and $1601 \mathrm{~cm}^{-1}$ band, assigned to other organic residual compounds from the extraction protocol. The latter band provenience is the raw bark and not the solvents used as confirmed by the Raman analysis of different bark samples.

A wide range of Raman investigation of distinctive substances in several medicinal and aromatic plants have 


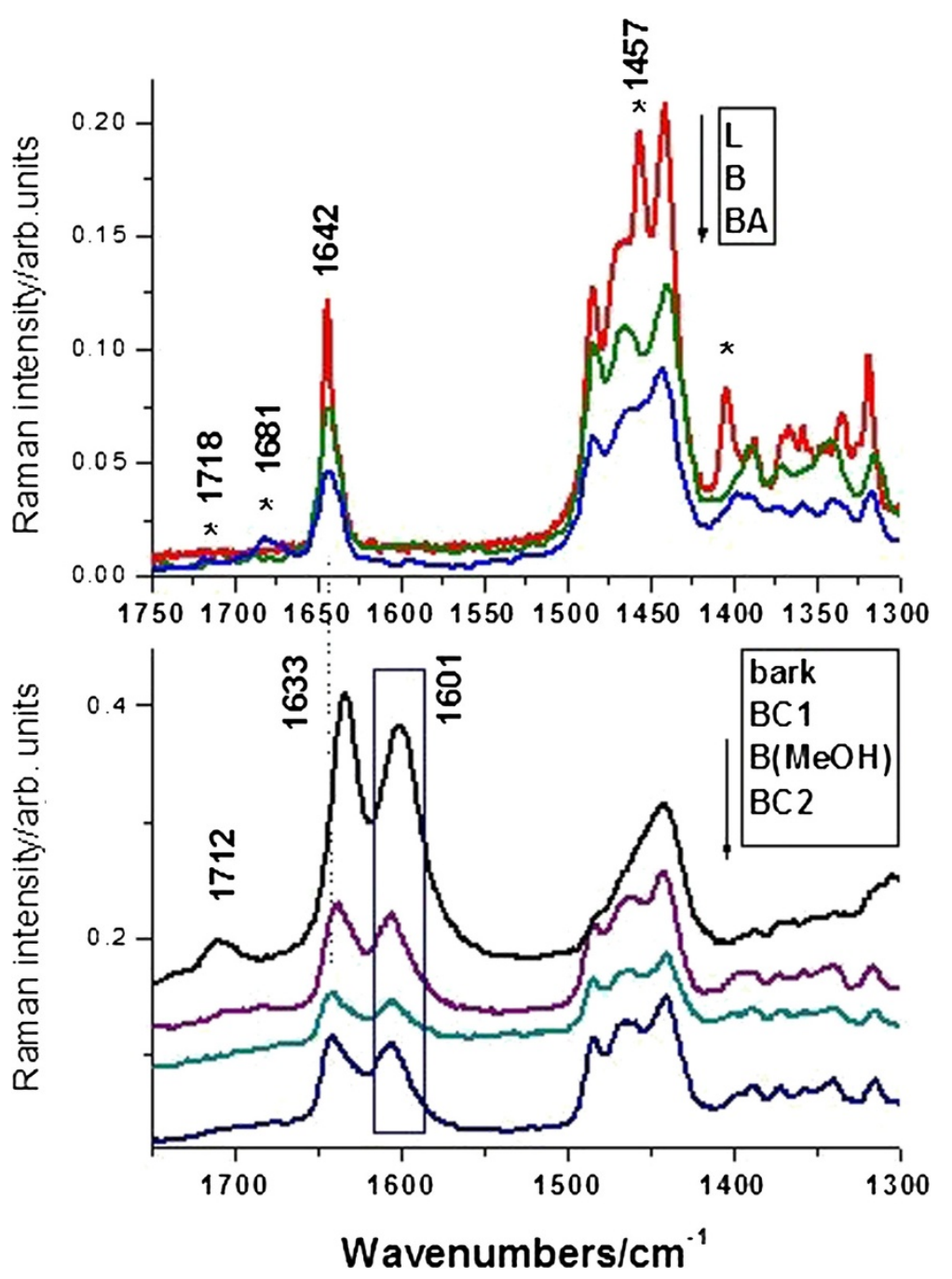

Figure 7 Low wavenumber range of the FT-Raman spectra of the $\mathrm{BC} 1, \mathrm{~B}(\mathrm{MeOH})$ and $\mathrm{BC} 2$ extracts and bark (bottom), compared with the reference spectra of betulin (B), lupeol $(L)$ and betulinic acid (BA), respectively (top). The arrow indicates the display order and the rectangle illustrate the band not attributable to triterpene species. Excitation: 350 mW, 1064 nm.

been reported [16-18,23] and the key Raman bands were discussed by comparison to the corresponding pure standard components. Raman spectra obtained directly from vegetal tissue by using laser excitation in the visible range are often completely covered by the huge fluorescence background and consequently, the inherent weak Raman scattered signal is not observable. To overcome such aspects, NIR laser sources such as laser diode $(785 \mathrm{~nm})$ or Nd:YAG laser emitting at $1064 \mathrm{~nm}$ are employed, or other Raman techniques, such as Resonance Raman or SERS [24] for the plants investigation with visible laser lines.

\section{GC/MS analysis of the extracts}

Mass spectra of betulin ( $M=442$, elution time $23.7 \mathrm{~min})$ and lupeol $(\mathrm{M}=426$, elution time $19.07 \mathrm{~min})$ are displayed in the Figures 8 and 9, respectively.
The separation chromatogram of the $\mathrm{BC} 1$ extract is also attached in the Figure 9. As expected, two major compounds, betulin $(58.8 \%)$ and lupeol $(41 \%)$ were dominant in the $\mathrm{BC} 1$ extract, as indicated by the mass spectra, whereas the other two extracts, $\mathrm{BC} 2$ and $\mathrm{B}(\mathrm{MeOH})$ respectively, exhibited less triterpene content [25] (22.8\% and $23.7 \%$ betulin, respectively), in agreement with the predicted vibrational data. The NIST library of spectra was used for reference.

The main observations regarding this study include the possibility of Raman techniques application for in detail elucidation of important antitumor compounds like pentacyclic triterpenes. Another important point is the possibility of comparison between important techniques like vibrational spectroscopy, gas chromatography on elucidation of extracts purity and their composition easy applicable even in case of pentacyclic triterpenes 


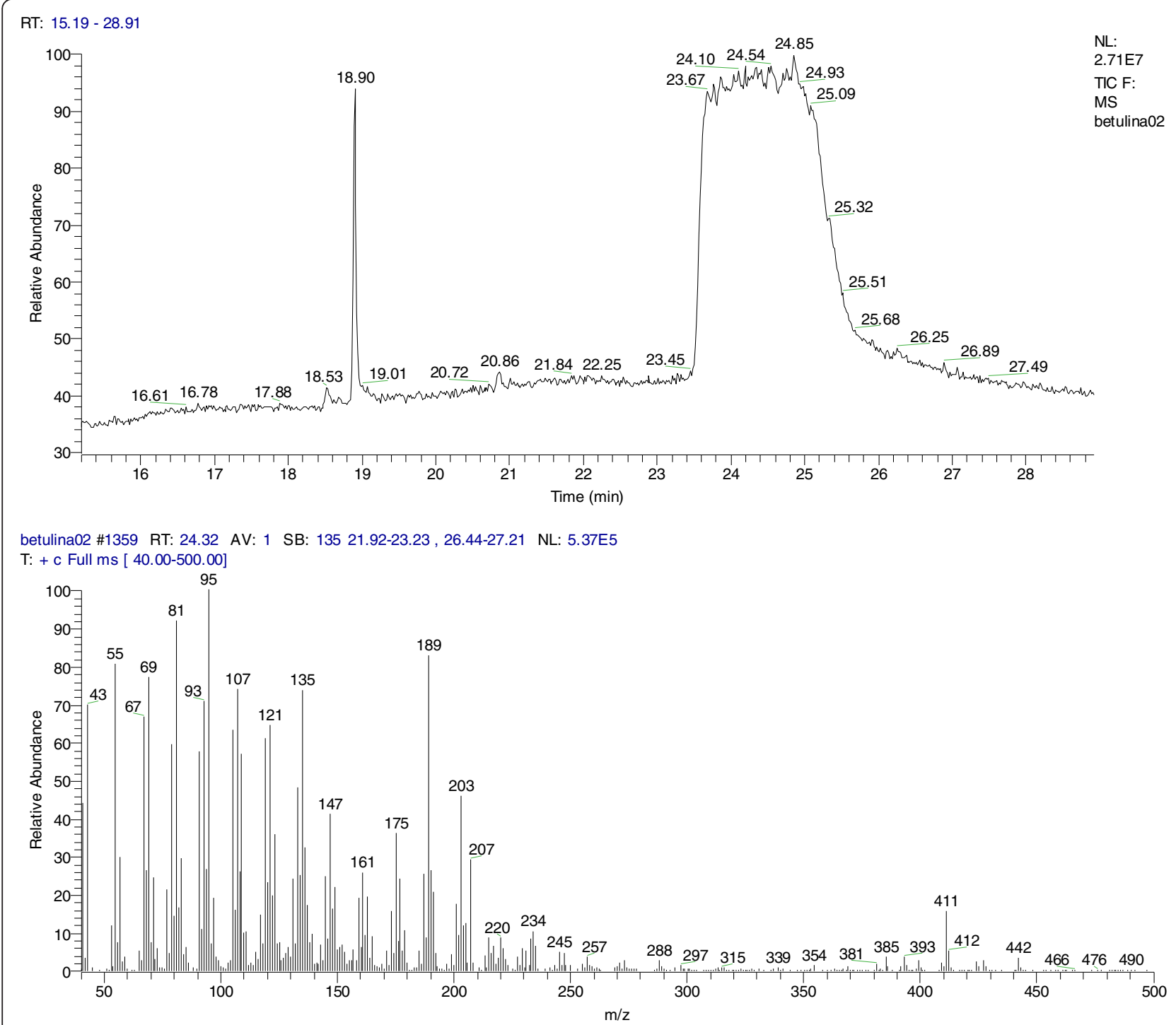

Figure 8 The chromatogram and mass spectrum of betulin (ethanol/methanol, elution time $23.7 \mathrm{~min}) . \mathrm{Tcol}: 50^{\circ} \mathrm{C}(1 \mathrm{~min}) 20^{\circ} \mathrm{C} / \mathrm{min} \mathrm{l}$; a $310^{\circ} \mathrm{C}(15 \mathrm{~min}) ; \mathrm{M}=442$.

with lupan skeleton. The elucidation for extraction procedure is an indicator about the most acceptable extraction route (e.g. solvent type, quantity, type of procedure). As we expected the extracts contain lupan skeleton triterpenes but their percentage in the extract differ because of the procedure and solvents. Continuous extraction seems to be the most quantitative for these compounds.

\section{Methods}

Plant material

The plant material, outer bark of birch tree, Betula pendula Roth, (Betulaceae) was harvested from the Aninei Mountains (Banat region, South Weastern of Romania) in October 2010. Voucher samples were deposited in the Herbarium of the Department of Pharmaceutical Botany of the Faculty of Pharmacy, University of Medicine and Pharmacy, Timisoara, voucher BB1265/10. Only the outer part of the bark (the cork) that spontaneously separates from the stem in autumn was used. The cork was air-dried at room temperature, broken in small pieces and ground into powder by a mill. All solvents were reagent grade. The raw sample of birch bark was collected from $4.85 \mathrm{~g}$ outer bark dried at room temperature. The extracts were prepared from the outer bark by Soxhlet extraction in methanol as solvent. $[8,24]$ BC1 sample was obtained from $5.01 \mathrm{~g}$ bark in $250 \mathrm{ml}$ methanol; the extraction has been performed for 2 hours. It was selected after comparation with another two types of extractions, using a Soxhlet (Gerhardt) continuos extraction: $\mathrm{BC} 2$ sample resulted from $4.93 \mathrm{~g}$ birch 


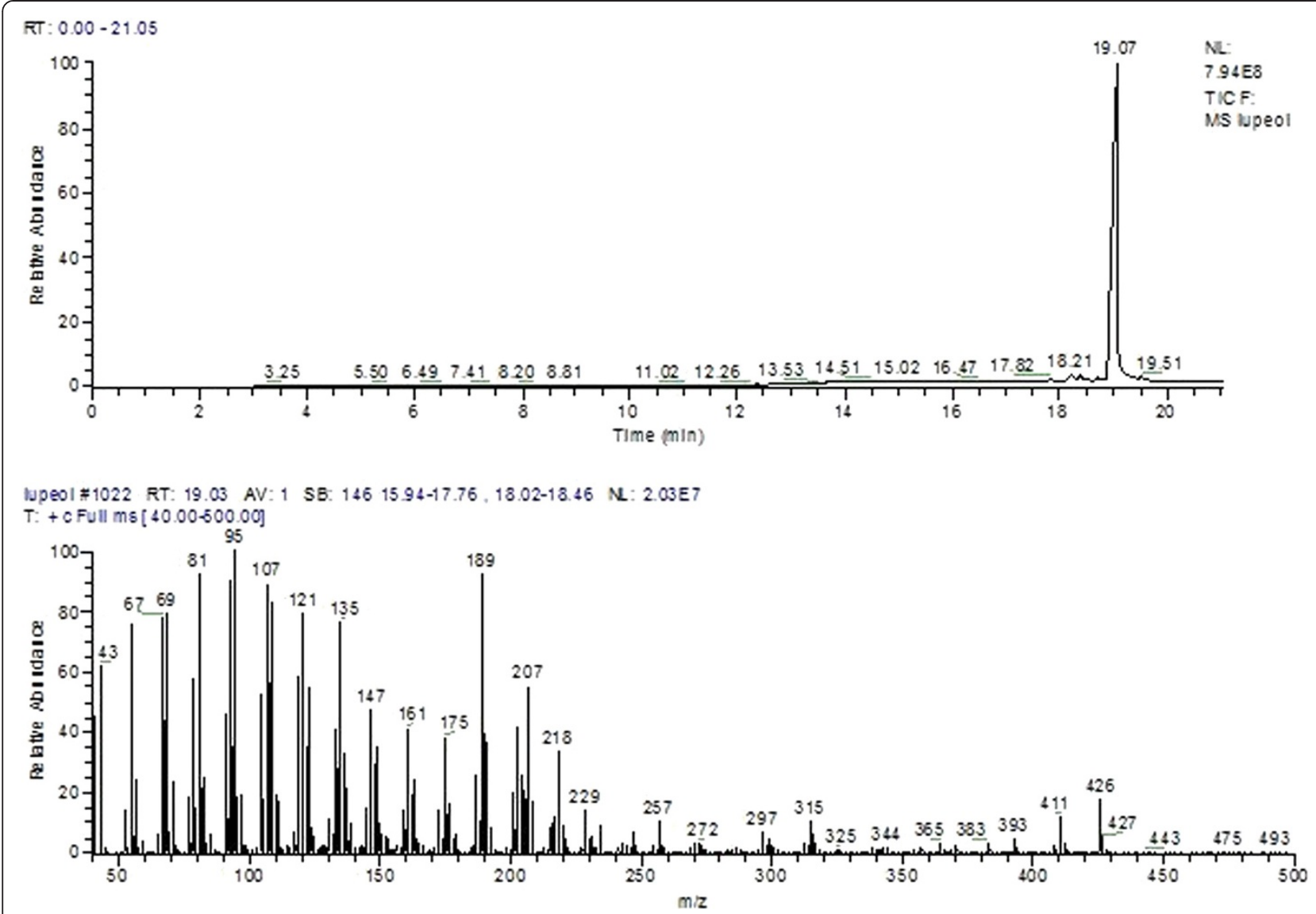

Figure 9 The chromatogram and mass spectrum of lupeol, (ethanol/methanol, elution time $19.07 \mathrm{~min}) . \mathrm{Tcol}: 50^{\circ} \mathrm{C}(1 \mathrm{~min}) 20^{\circ} \mathrm{C} / \mathrm{min} \mathrm{l;}$ a $310^{\circ} \mathrm{C}(15 \mathrm{~min}) ; \mathrm{M}=426$.

bark and $250 \mathrm{ml}$ cloroform/diclormetan/metanol 1:1:1 solvents mixture for 2 hours, continuous extraction and $\mathrm{B}(\mathrm{MeOH})$ sample from $4.90 \mathrm{~g}$ dried sample with $250 \mathrm{ml}$ methanol using a ultrasonication bath (Falc). According to the literature $[1,9,10,20,26]$ using a mixture of solvents could result in an increased extraction products amount but we proved that the continous methanolic extract assure a good extraction yield for triterpene content. [8] In order to establish the end of extraction, the depletion of vegetal material was used. The dried forms were obtained by using a Büchi rotary evaporator device. Additional bark samples from nine birch three (vouchers BB1291-1299/10) were collected in October 2010 for Raman measurements.

Isolation and GC-MS analysis of triterpenes has been achieved from the purified samples solved in methanol/ dichloromethane.

\section{Apparatus}

A Trace DSQ Thermo Finnigan quadruple mass spectrometer coupled with a Trace GC was employed for GC/MS analysis. A Rtx-5MS capillary column, $30 \mathrm{~m}$ length $\times 0.25 \mathrm{~mm}, 0.25 \mu \mathrm{m}$ film thickness was used in a temperature program from $50{ }^{\circ} \mathrm{C}$, kept 1 minute, then with $20^{\circ} \mathrm{C} /$ minute to $310{ }^{\circ} \mathrm{C}$, kept for $15 \mathrm{~min}$.

FT-IR and FT-Raman spectra have been recorded using an Equinox 55 Bruker spectrometer with an integrated FRA $106 \mathrm{~S}$ Raman module. A Nd:YAG laser operating at $1064 \mathrm{~nm}$ line was employed for the excitation of the powdered sample extract or the raw birch bark. The laser power was set to $350 \mathrm{~mW}$. An attenuated total reflectance (ATR) MIRacle module with ZnSe contact crystal has been coupled to the Equinox 55 FTIR Bruker spectrometer for the recording of the ATR-FT-IR absorbance spectra in the $4000-650 \mathrm{~cm}^{-1}$ range. The spectral resolution was $2 \mathrm{~cm}^{-1}$ and 40 scans were accumulated for each powder sample. The spectral data have been processed using Origin 8.0 software.

\section{Conclusions}

We employed vibrational FT-IR and FT-Raman spectroscopy as rapid, sensitive and efficient techniques for qualitative and semi-quantitative analysis of the pentacyclic triterpene based natural products as highly effective anticancer agents obtained from the Betula pendula Roth birch bark. Nine bark samples from the abundant 
forest flora of Apuseni Mountains, Romania were Raman evaluated concerning their triterpenes content. Additionally, three different extraction conditions have been applied for one birch bark specimen aiming to obtain the highest triterpene content in the extraction product. Methanol solvent and longer extraction time revealed the product with highest triterpene content as revealed by the vibrational analysis. The conclusions were supported by the GC-MS analysis that revealed two major compounds, betulin (59\%) and lupeol (41\%) in the highest purity extract.

All the three extracts presents similar main IR/Raman spectral fingerprint associated to the pure triterpenes, where betulin bands were dominant. Betulinic acid is less observable as distinct compound in the extraction product, on one hand, due to its low concentration and on the other hand due to the weak Raman intensity characteristic for the $-\mathrm{COOH}$ group at 1681 and $1718 \mathrm{~cm}^{-1}$.

Based on IR and Raman analyses, one can conclude that all the extracts, independent on the solvent(s) used, revealed dominant betulin species, followed by lupeol. Raman spectroscopy could provide semi-quantitative information concerning the triterpene content in the final extract products by analyzing the relative intensity ration of the $1642 \mathrm{~cm}^{-1}$ ( $\mathrm{C}=\mathrm{C}$ mode) and $1601 \mathrm{~cm}^{-1}$ band, assigned to other organic residual compounds from the bark. Since Raman measurements could also be performed on fresh plant material, we demonstrated the possibility to apply the present results for the prediction of the highest triterpene content in bark species, for optimal harvest time or for the selection of individual genotypes directly in the field, with appropriate portable Raman equipment.

\section{Competing interests}

The authors declared that they have no competing interests.

\section{Acknowledgement}

This study was supported by the CNCS-UEFISCDI Romania, projects PNII-PD537/2008 and PNII-PD-586/2010.

\section{Author details}

${ }^{1}$ Molecular Spectroscopy Dept., Babes-Bolyai University, 1st M. Kogălniceanu Str., Cluj-Napoca 400084, Romania. ${ }^{2}$ Faculty of Pharmacy, Victor Babeş University of Medicine and Pharmacy, 2nd Eftimie Murgu Sq., Timişoara 300041, Romania. ${ }^{3}$ Biomedical Physics Department, Babeş-Bolyai University, 1st M. Kogălniceanu Str., Cluj-Napoca 400084, Romania.

\section{Authors' contribution}

SCP carried out the analysis design and natural products screening studies. CAD conceived the study and participated in its design. CS participated in the analysis of the products and helped to draft the manuscript. MC and FB carried out the GC-MS analysis and participated in the interpretation of results. All authors read and approved the final manuscript.

Received: 26 April 2012 Accepted: 18 July 2012

Published: 18 July 2012

\section{References}

1. Yogeeswari P, Sriram D: Betulinic acid and its derivatives: A review on their biological properties. Curr Med Chem 2005, 12:657-666.
2. Berger S, Sicker D: Classics in spectroscopy: isolation and structure elucidation of natural products. Weinheim, Germany: Wiley-VCH Verlag; 2009.

3. Cichewicz RH, Kouzi SA: Chemistry, biological activity, and chemotherapeutic potential of betulinic acid for the prevention and treatment of cancer and HIV infection. Med Res Rev 2004, 24:90-114.

4. Krasutsky PA: Birch bark research and development. Nat Prod Rep 2006, 23:919-942.

5. Laszczyk MN: Pentacyclic Triterpenes of the Lupane, Oleanane and Ursane Group as Tools in Cancer Therapy. Planta Med 2009, 75:1549-1560.

6. Falamaş A, Cînta Pînzaru S, Dehelean CA, Peev Cl, Soica C: Betulin and its natural resource as potential anticancer drug candidate seen by FT-Raman and FT-IR spectroscopy. J Raman Spectrosc 2011, 42:97-107.

7. Alakurtti S, Mäkelä T, Koskimies S, Yli-Kauhaluoma J: Pharmacological properties of the ubiquitous natural product betulin. Eur J Pharm Sci 2006, 29:1-13.

8. Soica CM, Dehelean CA, Peev Cl, Aluas M, Zupko I, Kasa P, Alexa E: Physico-chemical comparison study of betulinic acid, betulin and birch bark extract and in vitro investigation of their cytotoxic effects towards skin epidermoid carcinoma (A431), breast carcinoma (MCF7) and cervix adenocarcinoma (HeLa) cell-lines. Nat Prod Res 2012, 26:968-974.

9. Dehelean CA, Cîntă Pînzaru S, Peev Cl, Soica C, Antal DS: Characterization of birch tree leaves, buds and bark dry extracts with antitumor activity. J Optoelectr Adv Mat 2007, 9:783-787.

10. Kovač-Bešović EE, Durić K, Kalođera Z, Sofić E: Identification and isolation of pharmacologically active triterpenes in Betulae Cortex, Betula pendula Roth., Betulaceae. Bosn J Basic Med Sci 2009, 9:31-38.

11. Sharma PP, Roy RK, Anurag B, Gupta D: Pentacyclic Triterpinoids from Betula utilis and Hyptis suaveolens. Int J PharmTech Res 2010, 2:1558-1562.

12. Schulz H: Rapid Analysis Of Medicinal And Aromatic Plants By NonDestructive Vibrational Spectroscopy Methods. Acta Hort (ISHS) 2005, 679:181-187.

13. Nafie LA: Recent advances in linear and nonlinear Raman spectroscopy. Part IV. J Raman Spectrosc 2010, 41:1566-1586.

14. Kiefer W: Recent advances in linear and non-linear Raman spectroscopy. Part III. J Raman Spectrosc 2009, 40:1766-1779.

15. Kiefer W: Recent advances in linear and nonlinear Raman spectroscopy II. J Raman Spectrosc 2008, 39:1710-1725.

16. Kiefer W: Recent Advances in linear and nonlinear Raman spectroscopy I. J Raman Spectrosc 2007, 38:1538-1553.

17. Cîntă Pînzaru S, Leopold N, Kiefer W: Vibrational spectroscopy of betulinic acid HIV inhibitor and of its birch bark natural source. Talanta 2002, 57:625-631.

18. Schulz $H$, Baranska M: Identification and quantification of valuable plant substances by IR and Raman spectroscopy. Vib Spectrosc 2007, 43:13-25.

19. Boik J: Natural Compounds in cancer therapy. Princeton, U.S.A: Oregon Medical Press; 2001.

20. Dehelean CA, Tatu C, Cîntă Pânzaru S, Peev Cl, Soica C, Tanasie G, Anghel S: In vitro studies on mesenchymal stem cells of a dry birch tree bark extract. Toxicol Lett 2006, 164:S228.

21. Mukherjee R, Kumar V, Srivastava SK, Agarwal SK, Burman AC: Betulinic acid derivatives as anticancer agents: structure activity relationship. Anti-Cancer Agents Med Chem 2006, 6:271-279.

22. Zhao G, Yan W, Cao D: Simultaneous determination of betulin and betulinic acid in white birch barkusing RP-HPLC. J Pharm Biomed Anal 2007, 43:959-962.

23. Schrader B, Schulz H, Andreev GN, Klump HH, Sawatzki J: Non-destructive NIR-FT-Raman spectroscopy of plant and animal tissues, of food and works of art. Talanta 2000, 53:35-45.

24. Rosch P, Popp J, Kiefer W: Raman and surface enhanced Raman spectroscopic investigation on Lamiaceae plants. J Mol Struct 1999, 480-481:121-124.

25. Dehelean CA, Peev Cl, Soica C, Tatu C, Cinta Pinzaru S, Gruia AT: Preliminary studies on mesenchymal stem cells and melanoma cells dry birch tree bark extract. Farmacia 2007, 6:696-702. LV.

26. Ciurlea S, Soica C, lonescu D, Ambrus R, Feflea S, Dehelean CA: Birch tree outer bark, a natural source of bioactive pentacyclic triterpenes with an antitumor activity. J Agroalim Proc Technol 2010, 16:328-332.

doi:10.1186/1752-153X-6-67

Cite this article as: Cîntă-Pînzaru et al:: Evaluation and differentiation of the Betulaceae birch bark species and their bioactive triterpene content using analytical FT-vibrational spectroscopy and GC-MS. Chemistry Central Journal 2012 6:67. 